\title{
REDACCIÓN HIPERTEXTUAL EN EL PERIODISMO DIGITAL UNIVERSITARIO: ACN, ESCENARIO, DIRECTO BOGOTÁ Y PAPIRO.
}

\section{Mireya Baron Pulido}

\section{RESUMEN}

Periodismo electrónico, Periodismo on-line, Periodismo digital son algunas de las acepciones más comunes al referirse al ejercicio de la escritura periodística que usa la internet.

Al revisar el contexto social en los procesos en los que emergen las dinámicas de la comunicación es necesario recordar el paso de la sociedad industrial a la sociedad informacional ${ }^{1}$; aquella en donde la información se convierte per sé en generadora y dinamizadora de sus niveles de productividad y de poder.

Resulta oportuno revisar estas relaciones en los países de América Latina, partiendo de los sistemas de economía agraria y/o acceso-sencillez-proximidad a la información a través de internet.

Conscientes de que este proceso mediático supera el hecho de montar una simple infraestructura, se trata de constatar las dinámicas que caracterizan a nuestros sistemas educativos, sistemas de las nuevas tecnologías y ciencia, contenidos para laciudadanía y contexto administrativo de dicho bagaje informacional.

Es hora de revisar el comportamiento e incursión de esa praxis en el ámbito universitario, toda vez que se convierte en el escenario potenciador de la formación en competencias profesionales del periodista del siglo XXI en la región.

El actual artículo recoge los resultados de la investigación cualitativa realizada en cuatro periódicos on-line de las facultades de Comunicación Social en Bogotá.

Se pretende evidenciar el comportamiento de tres elementos neurálgicos en la redacción del periodismo on-lineuniversitario: niveles de hipertextualidad, de multimedialidad y de interactividad.

Lectura detallada, captura de la estructura de pantalla principal de los artículos en cada periódico digital y cotejo con las sesiones de los cuatro respectivos grupos focales emisores, hacen parte de la metodología utilizada para ver las características de la narrativa ciberperiodística en mención.

Esta fase inicial permitirá determinarar el comportamiento de un ciberperiodismo forjado desde la academia con miras a alimentar una segunda investigación²: Análisis de Contenido -AC - haciendo uso del software Qualrus con el propósito de constatar la sintaxis digital que estructuran los hiperdocumentos en la línea periodística de estos ciberproductos.

Este recorrido investigativo permitirá argumentar la existencia y relaciones entre los niveles de multimedialidad e interactividad que dinamizan la tendencia de la narrativa hipertextual en el periodismo on-line universitario.

\section{ABSTRACT:}

Analysis made by the Director of the Family Compensation Fund Compensar, Néstor Rodríguez Ardila. Text taken from his intervention in the last Health Forum, held in Paipa, Boyacá in August 2008. This text will be part of the proceedings of such conference being published periodically by the Politécnico Grancolombiano, the Scenario Corporation, and the National Planning Department in order to socialize these academic discussions widely. This text analyzes the way public policies, conceived to preserve the institutional environment in Colombia, can generate the detriment in those institutions that provide health services. It also analyzes the different incentives considered in the Colombian health system along with its benefits and problems.

\section{PALABRAS CLAVE}

Periodismo Digital Universitario

\section{KEWORDS}

Health, resources, finances, institutional environment

1. En todas las sociedades ha habido información, advierte Castells. Consultado en: RUBIO L, María, Documentación Informativa en el Periodismo Digital, Madrid, Ed., Síntesis, pág. 212. 17., 2007.

2. Esta segundo objeto de investigación se implementará una vez se compilen los datos en el software de análisis cualitativo y se comparen con la actual investigación. 
Sea esta la oportunidad de encuentro con la academia y las redes de investigación en comunicación para ofrecer una mirada cualitativa de lo que cada uno de estos ejercicios percibe como lectura de realidad social desde la narrativa hipertextual.
Aunque el ciberperiodismo se encuentra en un proceso de gestación, no debemos desconocer los elementos que empiezan a caracterizar la narrativa en este ejercicio periodístico inclusive en el ámbito universitario, espacio forjador de los futuros profesionales del periodismo.

Tomando como punto de referencia la definición de hipertexto como "una combinación de nodos textuales que ofrece itinerarios diversos al lector, que configura así su propio relato.” (Diaz-Noci, 2006 página 215), tendremos en cuenta lo que para algunos expertos como Ramón Salaverría y Joyceleine Urdaneta (Canavilhas, João (2008), Editorial, Concha 2007) ya reconocen como características neurálgicas de la narrativa periodística digital: criterios de hipertextualidad, de multimedialidad y de interactividad.

\section{PROBLEMA DE LA INVESTIGACIÓN}

Teniendo en cuenta dos fenómenos de contexto: la ruptura del periodismo hacia la década de los $60^{3}$ y la incursión en las

\section{RESEÑADEAUTOR}

Mireya Baron Pulido (mbaronpu@poligran.edu.co). Licenciada en Ciencias de la Educación con Especialidad en Lingüística y Literatura Española. Magister en Lingüística Española e Hispánica del Instituto Caro y Cuervo-Seminario Andrés Bello. Estudió traducción en la Universidad Javeriana y en la Sorbona de París. Docente investigadora en el área de Periodismo. Miembro de Red Colombiana de Investigadores en Colombia Redicom. Entre sus investigaciones aparecen: "La ciudad desde el periodismo local universitario, un caso"; y "Redacción hipertextual en periodismo on line universitario", proyecto en ejecución. Docente de tiempo completo, adscrita al Departamento de Comunicación del Politécnico Grancolombiano. Actualmente es Directora de Grupo Comunicación Estratégica y Creativa de la Facultad de Ciencias de la Comunicación y Artes.. década de los 90 de una práctica periodística on line en las Facultades de Comunicación en América Latina con currículos que ofertan énfasis en Periodismo on line, o con asignaturas que potencian competencias desde las TICS- nuevas tecnologías, surge el siguiente interrogante por indagar:

¿Cuáles son los elementos discursivos que caracterizan la redacción hipertextual del periodismo on line de $A C N$ Agencia Central de Noticias, Directo Bogotá, Escenario, y Papiro, en las Facultades de Comunicación Social de las Universidades Fundación Universiad Central, Pontificia Universidad Javeriana, Santo Tomás y Politécnico Grancolombiano de Bogotá?

Aprovechando los espacios editoriales de nuestra institución, sea esta la oportunidad de encuentro con la academia y las redes de investigación en comunicación para ofrecer una mirada cualitativa de lo que cada uno de estos ejercicios percibe como lectura de realidad social desde la narrativa hipertextual.

La eclosión de un nuevo medio: la internet, la literatura que intenta dimensionar la retórica ciberperiodística, la temática convocante en eventos académicos nacionales e internacionales y la incursión del ciberperiodismo en los currículos de las facultades de comunicación en Ibero América y hoy en América Latina; son razones neurálgicas para empezar a dar evidencia empírica del comportamiento narrativo en dicha praxis del periodismo, y de manera específica en el periodismo formado desde la academia.

Por ello, y sin querer rebasar lo que ya algunos expertos han propuesto como las

3. Preservar o no los clásicos formatos periodístico en papel y el uso de la pirámide invertida. GONZÁLEZ, Gustavo, El Hiperperiodista en la Era del Hipertexto. Consultado en: http://www.periodismo.uchile. $\mathrm{cl} /$ asepecs/ponencias/2pggu.htm 
cuatro características básicas de la redacción en el periodismo desde el componente lingüístico (Diaz-Noci, 2006), queremos mencionar de lo que consta cada una de ellas:

a. Criterios hipertextuales: Existencia de nodos (visual-sonoro, audiovisual, websites) y enlaces. Algunos minuciosos autores, destacan la teoría de la coherencia intranodal, internodal e hiperestructural, como lo sugiere Martín Engebretsen ${ }^{4}$; y la tipología de hipervínculos.

b. Criterios de multimedialidad: Posibilidad de integrar en una misma estructura hipertextual nodos visuales, sonoros, o de otro tipo. Se debe incluir la interfaz como puente entre el lector y el sistema (emisor).

c. Interactividad: La posibilidad de que, a demandas del usuario, el sistema responda adaptando el mensaje a sus necesidades. También actúa la interfaz al servicio del lector; de la participación.

d. Temporalidad: La posibilidad de renovación del mensaje, se ingresa en una polisincronía que modifica las relaciones emisor-lector.

La existencia y la relación entre cada uno de estos elementos permitirá argumentar lo que realizan en la actualidad las facultades de Comunicación de la localidad de Chapinero enBogotá, caso que alimentará el comportamiento de las realidades ciberperiodísticas del ámbito universitario.

Para ello, organizamos los datos obte- nidos en cada uno de los ciberperiódicos analizados al momento, en tres gráficos:

- La Tabla 1, relaciona la existencia de dichos elementos.

- La Tabla 2 destaca la percepción de los emisores como grupo focal indagado ante la narrativa digital, en sus respectivos ejercicios periodísticos.

- Las 4 imágenes visualizan la captura de la Pantalla principal del artículo en cada uno de los productos ciberperiodísticos, tomando como muestra sincrónica, la edición culminada, que para la mayoría del corpus seleccionado corresponde a noviembre de 2007, con excepción de Papiro que inicia en el 2008 una edición semanal. La edición de Directo Bogotá se reanudará en el II del 2008.

Agradecemos la receptividad de los docentes, estudiantes, webmasters y diagramadores de las respectivas facultades que con su tiempo e información aportaron a la consecución de la investigación.

Las direcciones del corpus ciberperiodístico han variado algunos componentes desde el 2007 a la fecha, sin embargo se preserva la estructura básica:

- http://www.acn.almacreativa.org (U. Central)

- http://www.javeriana.edu.co/Facultades/ comunicacion_lenguaje/directo_bogota/

(U. Javeriana)

- http://fcsp.usta.edu.co/web_escenario5/ (U. Santo Tomas)

- http://www.poligran.edu.co/papiro/ (U. Politécnico Grancolombiano)

4. Martin Engesbretsen, "Hypernews and Coherente", Journal of Digital Information, Volume 1, Issue 7. Consultado en: http://jodi.tamu.edu/Articles/v01/i07/Engebretsen/index.php (Fecha de consulta: 05/10/008) 




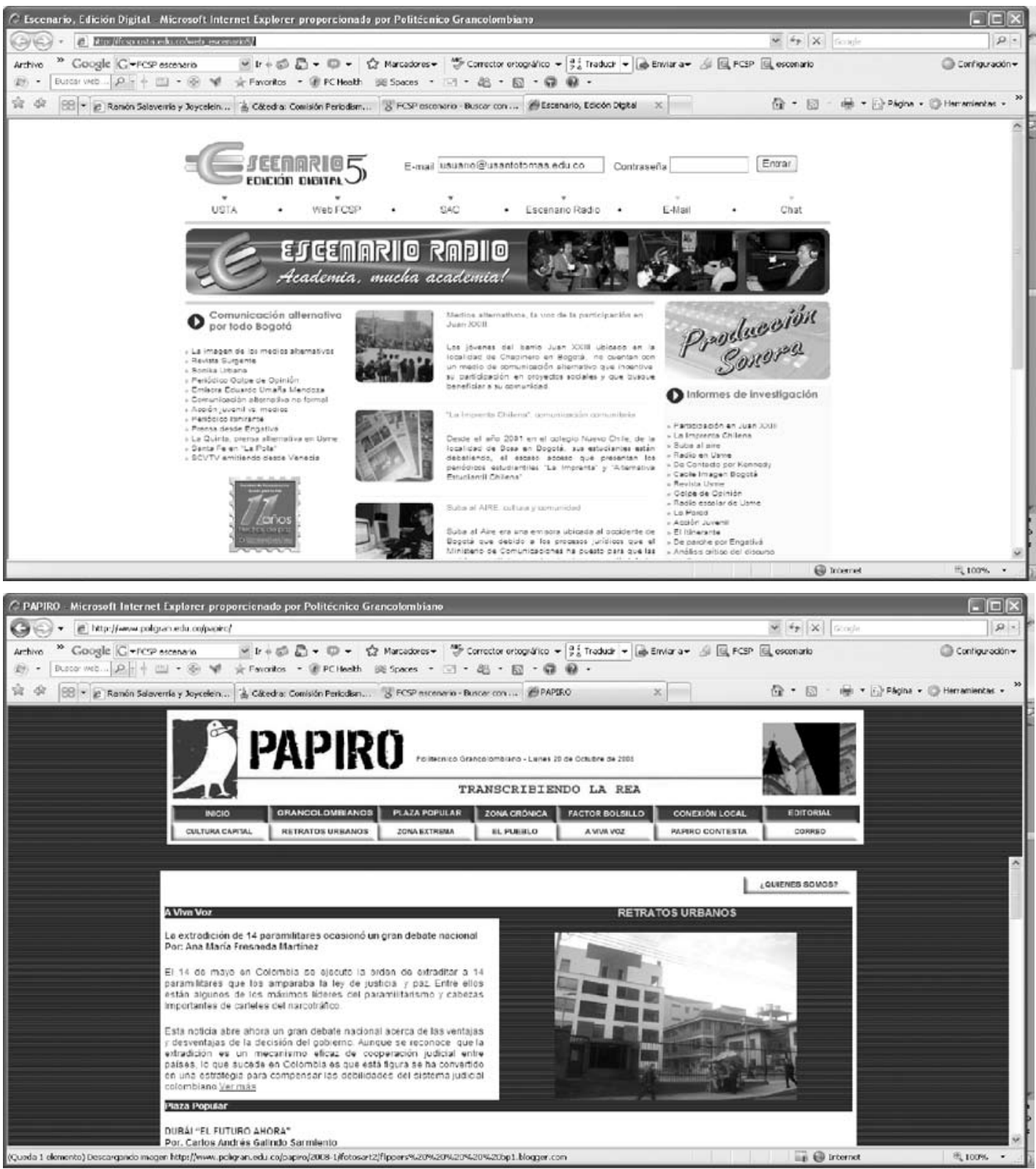

Para obtener los datos de la Tabla 1, se acudió a la lectura detallada de la pantalla y de los artículos de los cuales se destacaron los referentes (sujeto, objeto, tiempo, espacio) más frecuentes acordes con la misión de cada periódico, aspectos que se pueden implementar con la Tabla 2, que preserva algunas expresiones originales de las transcripciones y registros audiovisuales realizadas en las sesiones con cada grupo emisor. Estos registros se compilaron con la gestión del grupo semillero estudiantil del programa de Comunicación SocialPeriodismo de VII y IX semestre: Margarita Uribe, Pamela Zabala, Luis Palomino y Natalia Puentes. 


\begin{tabular}{|c|c|c|c|c|}
\hline Caracterización & ACN & Directo Bogotá & Escenario & Papiro \\
\hline $\begin{array}{l}\text { pantalla inicio } \\
\text { del periódico }\end{array}$ & $\begin{array}{l}\text { cabezote+nombres } \\
\text { de secciones y } 3 \\
\text { columnas: título de } \\
\text { artículo+sumario } \\
\text { +foto }\end{array}$ & $\begin{array}{l}\text { cabezote y } 4 \text { colum- } \\
\text { nas: bocadillo de } \\
\text { secciones+foto de } \\
\text { artículo,titular links, } \\
\text { sumario. enlace } \\
\text { ediciones anteriores. } \\
\text { enlace edición impre- } \\
\text { sa de directo Bogotá }\end{array}$ & $\begin{array}{l}\text { cabezote+ } 4 \\
\text { enlaces(correo- } \\
\text { chat-foro-facul- } \\
\text { tad) + números } \\
\text { anteriores+inicio+ } \\
\text { lista de artículos }\end{array}$ & $\begin{array}{l}\text { cabezote y secciones } \\
+ \text { galería de retratos } \\
\text { urbanos. sumario de } \\
\text { artículos+ bocadillo } \\
\text { de entidades de } \\
\text { comunicación y de la } \\
\text { localidad }\end{array}$ \\
\hline $\begin{array}{l}\text { pantalla del } \\
\text { artículo }\end{array}$ & $\begin{array}{l}\text { cabezote, } 3 \text { colum- } \\
\text { nas: título del } \\
\text { artículo+sumario+ } \\
\text { foto }\end{array}$ & $\begin{array}{l}\text { cabezote, } 3 \text { colum- } \\
\text { nas: bocadillo } \\
\text { de secciones, } \\
\text { artículo+correo del } \\
\text { escritor +blog }\end{array}$ & $\begin{array}{l}3 \text { columnas: multi- } \\
\text { media+ artículo + } \\
\text { enlaces de la facul- } \\
\text { tad y de a acecs }\end{array}$ & $\begin{array}{l}\text { cabezote con } \\
\text { las secciones. } \\
\text { artículo+enlaces multi- } \\
\text { media+ enlace a otros } \\
\text { artículos por sección }\end{array}$ \\
\hline $\begin{array}{l}\text { secciones del } \\
\text { periódico }\end{array}$ & $\begin{array}{l}\text { inicio, vida de hoy, } \\
\text { deportes, análisis } \\
\text { de medios, reforma } \\
\text { tributaria, narra- } \\
\text { tivas, entrevista, } \\
\text { cultura, opinión, } \\
\text { Colombia, cine, a } \\
\text { fondo, publicar, } \\
\text { videos }\end{array}$ & $\begin{array}{l}3 \text { bocadillos: : histo- } \\
\text { rias urbanas, entre- } \\
\text { tenimiento y opinión. } \\
\text { cada uno con sus } \\
\text { secciones }\end{array}$ & no aplica & $\begin{array}{l}\text { editorial, grancolom- } \\
\text { bianoplaza popular, } \\
\text { zona crónica, factor } \\
\text { bolsillo, conexión } \\
\text { local, zona extrema, } \\
\text { el pueblo, a viva voz, } \\
\text { retratos urbanos }\end{array}$ \\
\hline $\begin{array}{l}\text { temática de } \\
\text { artículos }\end{array}$ & social y crítica & $\begin{array}{l}\text { diversos géneros } \\
\text { narran el panorama } \\
\text { urbano de la ciudad, }\end{array}$ & $\begin{array}{l}\text { investigación urbano- } \\
\text { social }\end{array}$ & $\begin{array}{l}\text { agenda informativa } \\
\text { de la ciudad }\end{array}$ \\
\hline interactividad & $\begin{array}{l}\text { correo, sección } \\
\text { publicar para } \\
\text { enviar material } \\
\text { periodistico }\end{array}$ & $\begin{array}{l}\text { correo+blog del } \\
\text { escritor. vínculo } \\
\text { contáctenos }\end{array}$ & $\begin{array}{l}\text { chat, correo, foro, } \\
\text { facultad }\end{array}$ & $\begin{array}{l}\text { correo y blog del } \\
\text { escritor }\end{array}$ \\
\hline $\begin{array}{l}\text { tipos de enlace } \\
\text { (nodos) }\end{array}$ & $\begin{array}{l}\text { el artículo tiene } \\
\text { enlace con otro } \\
\text { texto e inclusive } \\
\text { enlaza hasta } 7 \\
\text { textos }\end{array}$ & $\begin{array}{l}\text { el artículo vincula a } \\
\text { otro texto. predomina } \\
\text { el enlace fotográfico, } \\
\text { le sigue audio y por } \\
\text { último video }\end{array}$ & $\begin{array}{l}\text { el artículo no tiene } \\
\text { enlaces. al costado } \\
\text { izquierdo de la panta- } \\
\text { lla aparecen vínculos } \\
\text { a fotografía, video y } \\
\text { audio }\end{array}$ & $\begin{array}{l}\text { en 2007: sumario y } \\
\text { vínculo "ver más". } \\
\text { predomina la fotogra- } \\
\text { fía y la infografía. En } \\
\text { 2008, audio para las } \\
\text { entrevistas }\end{array}$ \\
\hline $\begin{array}{l}\text { referentes } \\
\text { temàticos }\end{array}$ & $\begin{array}{l}\text { predomina referen- } \\
\text { cia espacial para } \\
\text { las crónicas de } \\
\text { lugar }\end{array}$ & $\begin{array}{l}\text { predomina la refe- } \\
\text { rencia de sujeto, } \\
\text { porque su género } \\
\text { dominante es la } \\
\text { crónica. }\end{array}$ & \multicolumn{2}{|c|}{$\begin{array}{l}\text { todos los artículos tienen referencias de suje- } \\
\text { to, espacio y objeto }\end{array}$} \\
\hline
\end{tabular}


TABLA2: ENTREVISTA INTENSIVA A GRUPOS EMISORES

\begin{tabular}{|c|c|c|c|c|}
\hline $\begin{array}{l}\text { Periódico } \\
\text { pregunta }\end{array}$ & ACN & Directo Bogotá & Escenario & Papiro \\
\hline misión & $\begin{array}{l}\text { experimentar con una } \\
\text { narrativa de calidad }\end{array}$ & $\begin{array}{l}\text { espacio de pasantía } \\
\text { "aprender haciendo" y } \\
\text { entrenamiento al entor- } \\
\text { no laboral en periodis- } \\
\text { mo digital }\end{array}$ & $\begin{array}{l}\text { divulgación de tipo } \\
\text { multimedia en la } \\
\text { red mundial de } \\
\text { computadores }\end{array}$ & $\begin{array}{l}\text { taller del estudian- } \\
\text { te para el estudian- } \\
\text { te con visión crítica } \\
\text { de la realidad }\end{array}$ \\
\hline redactores & \multirow{2}{*}{$\begin{array}{l}\text { todo estudiante puede } \\
\text { enviar sus escritos. } \\
\text { No está supeditada a } \\
\text { ninguna asignatura. Es } \\
\text { abierto el ejercicio }\end{array}$} & $\begin{array}{l}\text { estudiantes de v-vii } \\
\text { semestre. Los docentes } \\
\text { hacen edición y revisan } \\
\text { redacción y producción }\end{array}$ & $\begin{array}{l}\text { estudiantes de v } \\
\text { semestre }\end{array}$ & \multirow{2}{*}{$\begin{array}{l}\text { estudiantes de vii } \\
\text { semestre. } \\
\text { inscribirse a opción } \\
\text { énfasis periodis- } \\
\text { mo I }\end{array}$} \\
\hline requerimientos & & $\begin{array}{l}\text { con manejo de lenguaje } \\
\text { para internet y conver- } \\
\text { gencia de lenguajes }\end{array}$ & $\begin{array}{l}\text { haber cursado } \\
\text { asignaturas de } \\
\text { redacción }\end{array}$ & \\
\hline periodicidad & $\begin{array}{l}\text { cultura digital: si ocu- } \\
\text { rre algo extraordinario } \\
\text { a la edición semestral, } \\
\text { se edita }\end{array}$ & $\begin{array}{l}2 \text { ediciones al semes- } \\
\text { tre. se trabajará con } \\
\text { Ceantic, centro de TICS } \\
\text { de la universidad. }\end{array}$ & $\begin{array}{l}1 \text { semestral (modu- } \\
\text { lar) aunque hay } \\
\text { actualizaciones } \\
\text { mensuales }\end{array}$ & $\begin{array}{l}\text { En } 2007 \text { era } \\
\text { semestral. En } 2008 \\
\text { es semanal sacan- } \\
\text { do } 16 \text { ediciones al } \\
\text { semestre }\end{array}$ \\
\hline $\begin{array}{l}\text { asignaturas de } \\
\text { curriculo }\end{array}$ & $\begin{array}{l}\text { diseño audiovisual, } \\
\text { laboratorio de imagen- } \\
\text { de sonido y de radio } \\
\text { digital, narrativas } \\
\text { digitales, }\end{array}$ & $\begin{array}{l}\text { guión para multimedia, } \\
\text { taller de tv y radio }\end{array}$ & edición digital & $\begin{array}{l}\text { prensa, redacción y } \\
\text { diseño digital }\end{array}$ \\
\hline lector & \multicolumn{4}{|c|}{$\begin{array}{l}\text { comunidad estudiantil universitaria colombiana y entorno familiar. En Papiro se invita a las } \\
\text { fuentes de los artículos }\end{array}$} \\
\hline hipertexto & $\begin{array}{l}\text { el formato actual no es } \\
\text { hipertexto }\end{array}$ & $\begin{array}{l}\text { aunque mantiene } \\
\text { cercanía con Directo } \\
\text { Bogotá en papel, se } \\
\text { espera diferenciar más } \\
\text { la redacción digital. la } \\
\text { unidad la brindan las } \\
\text { secciones }\end{array}$ & $\begin{array}{l}\text { el hipertexto es } \\
\text { crítica a la razón } \\
\text { instrumental aun- } \\
\text { que existe esce- } \\
\text { nario en papel, } \\
\text { son } 2 \text { contenidos } \\
\text { diferentes. }\end{array}$ & $\begin{array}{l}\text { La unidad la brinda } \\
\text { el enlace de foto/ } \\
\text { video }\end{array}$ \\
\hline $\begin{array}{l}\text { tipos de enlace } \\
\text { (nodo) }\end{array}$ & no aplica & $\begin{array}{l}\text { predomina el enlace de } \\
\text { audio; es incipiente el } \\
\text { uso de enlaces. }\end{array}$ & $\begin{array}{l}\text { predomina el } \\
\text { enlace texto. se } \\
\text { proyecta incre- } \\
\text { mentar vínculos }\end{array}$ & $\begin{array}{l}\text { Enlace de audio. } \\
\text { Según la temá- } \\
\text { tica se enlaza a } \\
\text { entidades locales, } \\
\text { nacionales y/o } \\
\text { internacionales }\end{array}$ \\
\hline mapa de inicio & $\begin{array}{l}\text { minimalista para evitar } \\
\text { distracción al cibern- } \\
\text { auta } \\
\end{array}$ & $\begin{array}{l}\text { se mantienen las sec- } \\
\text { ciones }\end{array}$ & se utilizan marcos & $\begin{array}{l}\text { Diseño moderno } \\
\text { con los colores de } \\
\text { la universidad }\end{array}$ \\
\hline géneros & crónica-reportaje & $\begin{array}{l}\text { predomina la crónica. } \\
\text { temas en frío. de la } \\
\text { urbe no son temas de } \\
\text { actualidad } \\
\end{array}$ & $\begin{array}{l}\text { predomina la noti- } \\
\text { cia y reportaje de } \\
\text { investigaciones }\end{array}$ & $\begin{array}{l}\text { En el 2008, se abre } \\
\text { espacio para todos } \\
\text { los géneros }\end{array}$ \\
\hline interactividad & $\begin{array}{l}\text { es incipiente aún. el } \\
\text { servidor etb ratifica } \\
\text { estadísticas de consulta } \\
\text { desde ee.uu }\end{array}$ & $\begin{array}{l}\text { e mail del escritor, } \\
\text { formulario en línea. }\end{array}$ & $\begin{array}{l}\text { vínculos del } \\
\text { periódico y de la } \\
\text { facultad }\end{array}$ & $\begin{array}{l}\text { Vínculo "Papiro } \\
\text { contesta" }\end{array}$ \\
\hline TIC- plataforma & \multicolumn{4}{|c|}{$\begin{array}{l}\text { En todos los casos hay un webmaster que diagrama en Dreamweaver , Adobe, PhotoShop y/0 } \\
\text { Macromedia Directo }\end{array}$} \\
\hline
\end{tabular}


De la existencia de esos niveles de multimedialidad, interactividad, temporalidad e hipertextualidad sugeridos en las Tablas 1 y 2 , podemos extraer las primeras inferencias:

- En cuanto a la hipertextualidad, aunque predomina el nivel internodal (exógeno al artículo), los grupos emisores son
"El periodista digital debe escribircon palabras, con sonidosy con imágenes (...) Debe ser periodista ante todo..."

Lina Manrique, Docente U. Javeriana Editora de nuevas tecnologías Editorial Norma S.A. conscientes de la necesidad de potenciar el nivel intranodal (desde el artículo).

- El vínculo de mayor reiteración es el textual y le sigue el audio. Aparecen la infografía y la fotografía. En menor escala, aparece el video como elemento que apoya el contenido del artículo.

- Se interactúa con el lector a través de espacios como el chat, el foro y el correo del periódico. No obstante, ya se incursiona en otros dos niveles de interactividad: correo y blog de cada redactor, lo cual augura mayores procesos dialógicos entre escritor-internauta. Queda una tarea por revisar, y es poder registrar los niveles de participación y su afectación en la redacción y contenido de los artículos.

- En cuanto a la temporalidad, la mayoría de los artículos al trabajar temas de interés para la ciudad, manejan "temas en frío", lo cual les permite actualizar la página cuando la editorial así lo requiera. Sin embargo, hay un solo periódico en línea universitario que ya está manejando periodicidad semanal.
Dejando un panorama inicial en el comportamiento de algunos de los elementos de la narrativa digital, como lo mencionan ya los expertos, hay todo un camino investigativo que seguir explorando en cada uno de los ejes de la sintaxis digital tales como pertinencia de nodos y enlaces, tipos de hiperdocumentos y niveles de interactividad, entre otros.

Por lo pronto, podemos ver un nivel aún incipiente de una narrativa ciberperiodística universitaria, tal y como se sugiere en el anexo imagenes de la pantalla principal del artículo de cada periódico.

Hay toda una labor para implementar o redimensionar por parte de las facultades de comunicación y de sus actores sociales: los futuros ciberperiodistas.

Conocedores de la incursión de los nuevos medios y formatos, permítasenos traer a primer plano una elemental pero compleja recomendación sugerida por uno de los colaboradores del periódico Directo Bogotá: "El periodista digital debe escribir con palabras, con sonidos y con imágenes (...) Debe ser periodista ante todo...”

Lina Manrique, Docente U. Javeriana Editora de nuevas tecnologías Editorial Norma S.A.

Esperamos avanzar en los variados y posibles objetos de investigación que emergen de una de las realidades del futuro profesional en comunicación y periodismo: el ciberperiodismo.

\section{BIBLIOGRAFÍA}

- BONILlA, E., y RODRIGUEZ P. Más allá del dilema de los métodos: la investigación en las ciencias sociales, Bogotá: Norma, 2005.

- LÉVY, Pierre. Cibercultura: La cultura de la sociedad digital, México: Anthropos, 2007. 
- PISCITELLI, Alejandro, "Los hipermedios y el placer del texto electrónico", En: Ciberculturas 2.0 en el área de las máquinas inteligentes. Buenos Aires: Paidós Contextos, 2002.

- WIMMER R., y DOMINICK, Joseph, Introducción a la investigación de medios masivos de comunicación. México: Thompson Learning, 2001.

\section{CIBERBIBLIOGRAFÍA}

- BARÓN, P. Mireya, "La ciudad desde el periodismo local universitario, un caso", En: http://www.jareviana.redicom.co

- DIAZ-NOCI, Javier, "Periodismo Digital” -Mesa 6. En: http://www.razonypalabra. org.mx/anteriores/n48/mesa6.html

- MONTEROS O. Felipe, "Periódicos Electrónicos Estudiantiles, una Ventana al Entendimiento Universitario. El Caso del Stuka Rakuda”. En: http://www. razonypalabra.org.mx/anteriores/n30/fmonteros.html

- PÉREZ-Luque Ma. y FORONDA Maider, "El Reto de crear noticias online: Análisis de la comunicación online actual y perspectivas de futuro", En: http://www.ucm. es/info/multidoc/multidoc/revista/cuad6-7/noticias.htm

- SALAVERRÍA, Ramón "De la pirámide invertida al hipertexto: hacia nuevos estándares de redacción para la prensa digital”, En: http://www.unav.es/fcom/ $\mathrm{mmlab} / \mathrm{mmlab} /$ investig/piram.htm

- ____________________, Prensa, diseñando el lenguaje para el ciberperiodismo. En: Revista Latinoamericana de Comunicación CHASQUI, Junio, № 86, 2004.

- Santoyo Mirna Leticia, Ciberprensa. En: http://www.razonypalabra.org.mx/n61/ varia/msantoyo.html

- http://www.cibersociedad.net/congreso

- http://www.unav.es/fcom/mmlab/mmlab/investig/piram.htm 